\title{
Adaptations in the Temporalis Muscles of Rabbits after Masseter Muscle Removal
}

\author{
P. GUELINCKX ${ }^{1}$. P. C. DECHOW 2.5 , R. VANRUSSELT ${ }^{3}$, and D. S. CARLSON ${ }^{4}$
}

${ }^{1}$ Center for Microsurgery, Universitair Ziekenhuis, St. Pieter, KUL, 3000 Leuven, Belgium; ${ }^{2}$ Department of Anatomy, Baylor College of Dentistry, 3302 Gaston Avenue, Dallas, Texas 75246; ${ }^{3}$ Grote Bergstraat 17, 3300 Tienen, Belgium; and ${ }^{4}$ Department of Orthodontics, School of Dentistry, The University of Michigan, Ann Arbor, Michigan 48109

\begin{abstract}
Masseter muscles were surgically removed in six young female rabbits so that we could study adaptations of the superficial temporalis muscles $(S T)$ to increased functional requirements. Eight weeks following surgery, we used morphological measurements, histochemistry, contractile properties in situ, and occlusal force in vivo to compare the muscles in the experimental animals and six control rabbits. Analysis of the results demonstrated a decrease in fatigability of ST after masseter myectomy. Incisal occlusal force decreased by 65\% during the first two weeks, and no recovery was observed during the following six weeks. At eight weeks post-surgery, the mass, twitch tensions, and tetanic tensions of ST were not significantly different from those of the controls. An increase in the percent of the cross-sectional area composed of fast fatigue-resistant fibers, a slower time-to-peak twitch tension, and a decrease in fatigability suggest an increase in oxidative metabolism. Analysis of these results suggests that muscles used for highly repetitious activities with submaximal loadings adapt to increased functional requirements by increasing fatigue-resistant properties.
\end{abstract}

J Dent Res 65(11):1294-1299, November, 1986

\section{Introduction.}

Several studies have examined skeletal adaptations in the craniofacial region associated with shifts in the level of masticatory activity. Three basic experimental approaches have been used, including: (1) myectomy (Washburn, 1947; Horowitz and Shapiro, 1951; Avis, 1959, 1961; Boyd et al., 1967); (2) nerve ablation or lesioning (Sarnat et al., 1977; Gardner et al., 1980; Behrents and Johnston, 1984); and (3) alteration of diet (Beecher and Corruccini, 1981; Bouvier and Hylander, 1981, 1982, 1984). Removal of the masseter or temporalis muscle has a local effect at the site of origin and insertion of the muscle. These sites fail to develop to the same extent as in normally growing individuals, and become atrophic in adults. The cause of the hypoplasia and atrophy remains unclear, since both interruption of blood supply and reduced biomechanical force produce similar morphological changes (Boyd et al., 1967; Vargervik and Miller, 1984). Removal of the masseter and temporalis has also been shown to have more wide-ranging effects on the growth and form of the craniofacial skeleton, suggesting that muscle function plays some role in the normal growth of this complex (Moore, 1965; Moss, 1972). Similarly, nerve ablation studies have demonstrated that unilateral loss of function is associated with skeletal hypoplasia, resulting in a craniofacial asymmetry (Gardner et al., 1980; Behrents and Johnston, 1984; Byrd and Luschei, 1980). Laboratory animals that were raised on soft diets, where presumably less masticatory muscle activity was required, have also been demonstrated to exhibit a reduction in bone growth and remodeling (Bouvier and Hylander, 1984).

Received for publication February 11, 1986

Accepted for publication June 6, 1986

${ }^{5}$ To whom correspondence and reprint requests should be addressed

This research was supported by USPHS Research Grants DE07761, DE03610, and DE05232 from the National Institute of Dental Research, National Institutes of Health, Bethesda, MD 20892.
Previous studies have been concerned primarily with the development, growth, and form of the craniofacial skeleton. None has been concerned with concomitant adaptations within the muscles of mastication themselves. Such adaptations are important, since they may precede and contribute to alterations in the growth and form of the craniofacial skeleton and soft tissues of the face.

Numerous studies of limb muscles have examined muscular adaptation to increased functional loads induced by ablation (for reviews, see Goldberg et al., 1975; Holloszy and Booth, 1976; Edgerton, 1978; Armstrong et al., 1979; Jolesz and Sreter, 1981; Salmons and Henriksson, 1981). These investigations have established that increased activity, either due to surgical overloading as a result of removal of synergistic muscles or due to weight training, results in muscle fiber hypertrophy and an increase in oxidative properties.

The purpose of this study was to evaluate, in growing rabbits, adaptations within the superficial temporalis muscles to increased functional requirements following ablation of the masseter muscles. It was hypothesized that: (1) the temporalis muscles adapt primarily by fiber hypertrophy and an increase in oxidative properties, and (2) this hypertrophy would lead to increased force-generating properties in order partially to compensate for loss of the masseter muscles in the production of occlusal force.

\section{Materials and methods}

Twelve eight-week-old healthy New Zealand white rabbits, six control and six experimental, were used for the study. The animals were followed for an eight-week period, and were then killed by an overdose of sodium pentobarbital. The animals were maintained in conventional rabbit cages and were allowed to eat (Purina Rabbit Chow) and drink ad libitum. Body weight was recorded at two-week intervals throughout the study.

Surgical procedures. - Bilateral masseter myectomy was performed on six of the eight-week-old rabbits (experimental group). The animals were anesthetized with an IM injection of a combination of ketamine $(35 \mathrm{mg} / \mathrm{kg})$ and xylazine $(8 \mathrm{mg} /$ $\mathrm{kg}$ ). Each masseter muscle was exposed surgically with the same midline submandibular incision. Each facial nerve was dissected and retracted, and the entire masseter muscle was removed. Care was taken to remove the deep portion of the masseter muscle originating under the zygomatic arch. Following adequate hemostasis, the incision was closed.

The experimental animals all received subcutaneous saline administration $(0.9 \% \mathrm{NaCl}$ plus $150 \mathrm{USP}$ units hyaluronidase) for four days post-operatively. All physiological measurements were made under the same conditions of anesthesia as those used for the surgical procedures.

Bite-force recordings. - In order to study changes in the force-producing capabilities of the masticatory muscles as a whole following masseter removal, we used a bite-force transducer and muscle stimulation procedure in vivo to measure stimulated incisal bite force in all animals at two-week intervals following surgery. The transducer and stimulation pro- 
cedure were modified from those described by Dechow and Carlson (1983). Platinum stimulation electrodes (Grass E2 Subdermal) were placed bilaterally in the bellies of the superficial temporalis muscles and the medial pterygoid muscles. Maximum incisal bite force (BF) was measured during muscle stimulations consisting of $0.2-\mathrm{ms}$ pulses for a $400-\mathrm{ms}$ duration. Stimulation voltages of 25 volts and $100 \mathrm{~Hz}$ were used to elicit a contraction of maximal force.

In situ contractile properties. - At the end of the experimental period, contractile properties of the superficial temporalis muscle (ST) were recorded in situ (Fig. 1). The heads of the rabbits were firmly immobilized in a head-holder, with each rabbit in a prone position. The skin on the top of the cranium was incised, elevated, and sutured to a metal ring to create a skin pouch that was filled with mineral oil. This approach allowed for measurement of ST contractile properties at a constant temperature of $37^{\circ} \mathrm{C}$. The ST tendon was resected just before it passed over the posterior root of the zygoma into the infratemporal fossa. The tendon was attached to a muscle force transducer by means of a non-distensible connecting wire. Platinum electrodes were placed in the muscle belly. Care was taken to leave the blood flow at the inferior border of the muscle intact. Stimuli were delivered over a small range of muscle lengths so that the position (Lo) of maximal twitch tension $(\mathrm{Pt})$ could be determined. Subsequently, all measurements of contractile properties were performed at this muscle length. Measurements included peak twitch tension $(\mathrm{Pt})$, timeto-peak tension (TPT), one-half relaxation time (HRT), and tetanic force (Po) (Fig. 2). Pulses were of 0.2-ms duration and 25-volt magnitude. Tetani were obtained with 400 -ms trains at $150 \mathrm{hz}$, which was sufficient to generate a fused tetanus. ST was also subjected to a fatigue test, during which a $3-\mathrm{Hz}$ stimulation protocol was used to fatigue the muscle for a fiveminute period. Pt was recorded after this period of repetitive stimulation and was compared between groups. A lethal dose of sodium pentobarbital was administered after measurement of contractile properties was completed.

Histochemical and histological studies. - Following measurement of contractile properties, ST was removed, weighed, and quick-frozen in isopentane cooled with dry ice. Fourteen$\mu \mathrm{m}$-thick serial cross-sections of the muscle, taken from the muscle belly midway between its two attachments, were cut in a cryostat at $-20^{\circ} \mathrm{C}$. Sections were then incubated for (1) myofibrillar ATPase activity with and without pre-incubation, at $\mathrm{pH} 10.2,9.4,4.6,4.5$, and 4.3, and (2) succinic acid dehydrogenase. Portions of ATPase histological sections were photographed by means of a $25 \times$ objective in a Zeiss Photomicroscope II, and 8-inch-by-10-inch prints were made of the entire negative to a standardized magnification $(\times 500)$. A composite of several micrographs was constructed of the entire cross-section of the muscle belly, and several regions in each composite were randomly selected for further examination (Fig. 3). Types I and II fibers were classified on the basis of staining intensity of myofibrillar ATPase at various $\mathrm{pH}$ conditions. Using the photomicrograph as a guide, we examined serial SDH sections for oxidative enzymes, and each Type II fiber was further separated into either Type IIa or IIb (Dubowitz and Brook, 1973). The ATPase photomicrograph was then used to determine the cross-sectional area of each fiber type by means of a digitizer (Summagraphics) interfaced with a microcomputer (Tektronics 4054). Approximately 250 to 400 cross-sections of muscle fibers per ST were digitized. The data for each muscle were treated as a single sample, and we determined (1) the mean area for each fiber type and (2) the relative crosssectional composition of ST by fiber type and area.

Additionally, the medial pterygoid muscle (MP) was removed in each animal and weighed. These weights were used as a measurement of differences in masticatory muscle size between the two groups.

Radiography. - Lateral and frontal cephalograms were taken of all animals at two-week intervals throughout the study in order to assess differences in craniofacial size and growth. Gross measurements of cranial size were taken from these radiographs at the end of the experiment. Cranial length and width were measured between alveolare and the most posterior point on the cranium and between both zygomatic arches, respectively.

\section{Results.}

During the eight weeks post-surgery, body weight in the control animals increased a greater amount than in the experimental animals. A $t$-statistic indicated no significant differences in weight prior to surgery, but there were significant differences eight weeks later (Table 1). However, these differences in gross weight had no apparent impact on differences in craniofacial size or growth. Measurements of cranial size (skull length and width) were not significantly different between experimental and control animals at either the beginning or the end of the experiment (Table 1). Similarly, ST and MP mass were not significantly greater in experimental animals than in controls (Table 1). For these reasons, we suspect that weight differences in the two groups at death do not reflect true differences in lean body mass. Accordingly, we did not normalize muscle mass or muscle force for differences in body weight.

Post-surgical measurements of occlusal force (Table 2) showed a significant difference between the control and experimental groups throughout the study. Both groups exhibited an increase in occlusal force with growth, although this increase was larger in the control group. However, the mean for the experimental group was approximately $40 \%$ of that of the control group for each set of measurements. These results indicate that approximately $60 \%$ of occlusal force was lost due to bilateral removal of the masseters, and that this functional deficit remained constant throughout the post-surgical period.

Measurements of the in vivo contractile properties in ST demonstrated statistically significant differences between groups

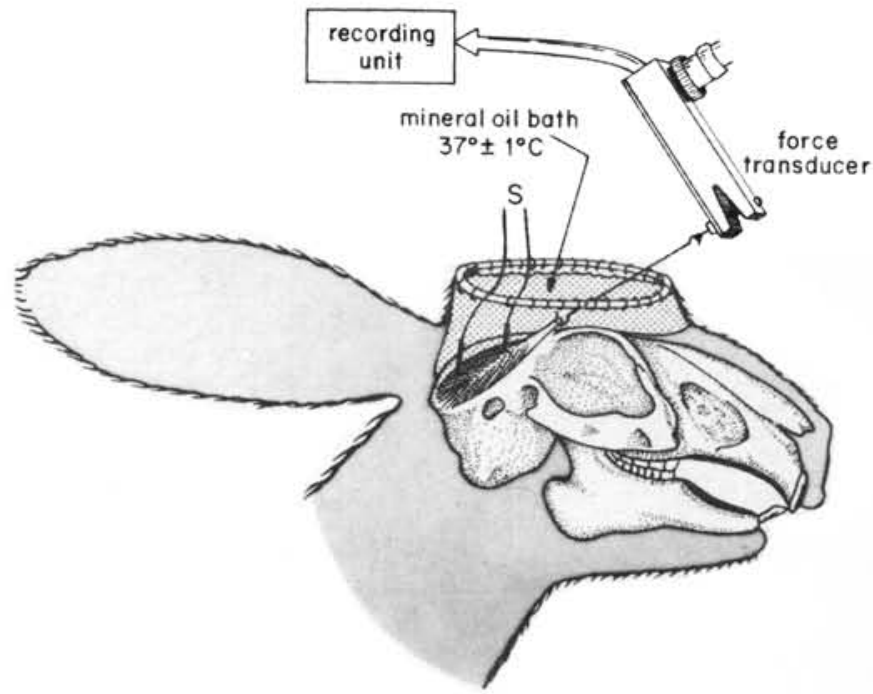

Fig. 1-Preparation for recording contractile properties from the superficial temporalis muscle of the rabbit. Not pictured here is the apparatus for immobilizing the rabbit's head. Stimulation electrodes (S) were placed directly in the muscle belly. 
Fig. 2-Examples of twitches and force-frequency relationships recorded for rabbit superficial temporalis muscles. Figures on the left are representative twitches for a control animal (top) and an experimental animal (masseter ablated) (bottom). Figures on the right are representative force-frequency relationships for a control animal (top) and an experimental animal (bottom). Recordings were taken at stimulation frequencies of $10,20,35,50,80,100,120$, and $150 \mathrm{~Hz}$. Po (maximum tetanic force) was measured at a stimulation frequency of $150 \mathrm{~Hz}$. Note that scales on the $\mathrm{Y}$-axis differ between figures.
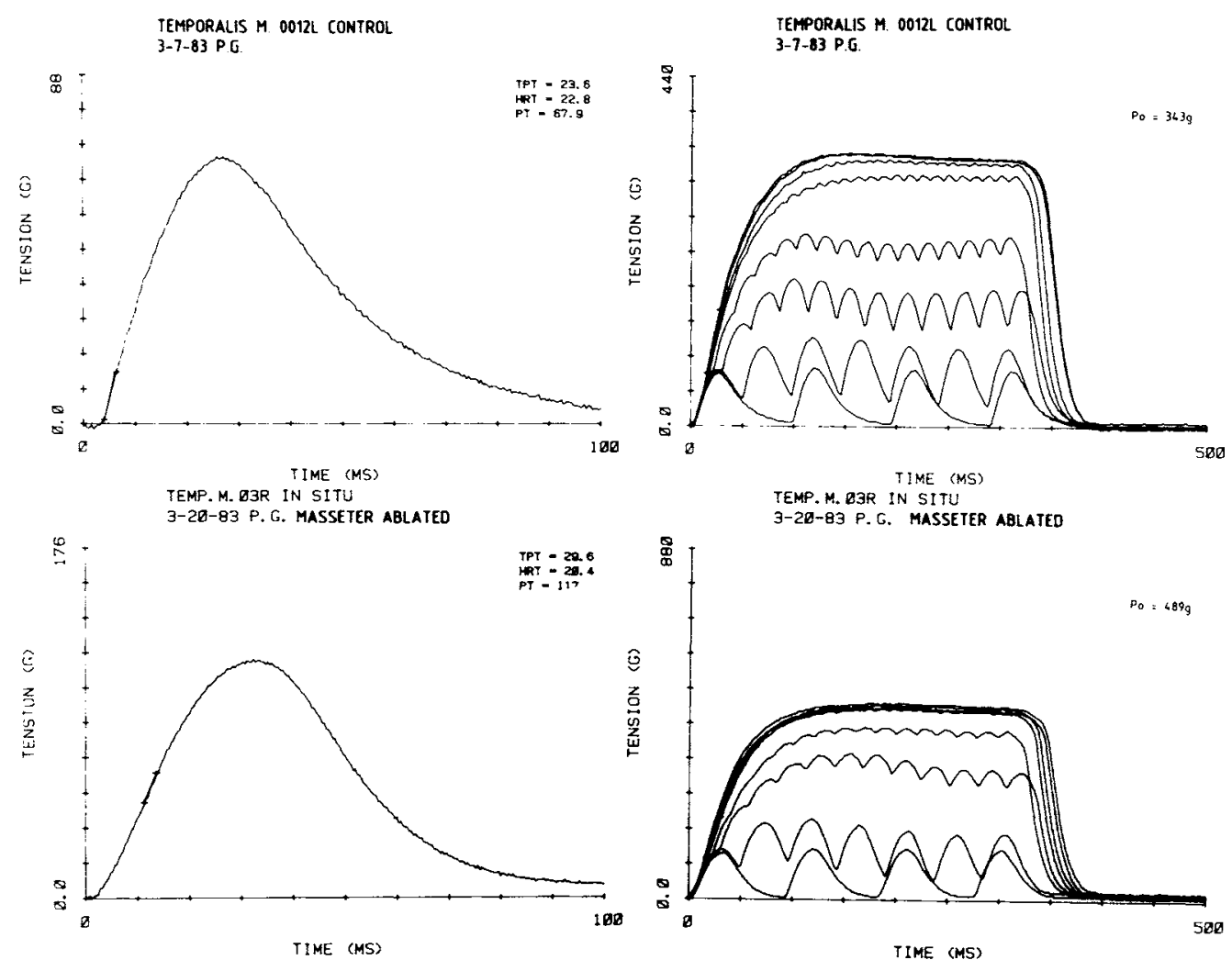

IEMPORALIS M. OO12L CONTROL
3-7-83 P.G.

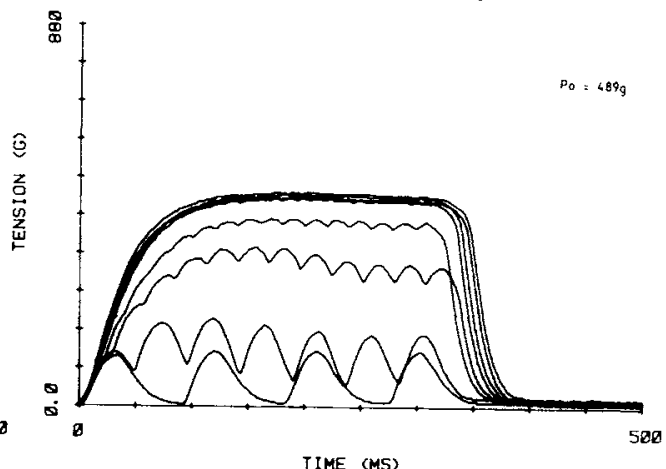

in TPT and in the final Pt reading (Table 3). Relative to controls, TPT was longer in the experimental group. Likewise, we expected to find a parallel difference in HRT between experimentals and controls. However, this was not the case; HRT was not significantly different between groups. After our protocol of fatiguing ST for five minutes by stimulating at $3 \mathrm{~Hz}$, Pt was significantly smaller in the experimental group. Prior to this stimulation protocol, no significant difference was seen between groups.

Histochemical and histological differences between control and experimental groups in ST were consistent with differences found in contractile properties. Although there were no significant differences found in the percent composition of ST by fiber type, the relative area occupied by Types IIA and IIb fibers did differ significantly between groups. The percent crosssectional area occupied by Type IIb fibers was less in the experimental group as compared with controls, while the proportions and percent area occupied by Type IIa fibers were greater (Table 4). Consistent with this finding, the experimental animals were found to have Type Ila fibers with average cross-sectional areas larger than those in the control animals.

\section{Discussion.}

Although several extensive studies have been conducted on gross masticatory muscle morphology and the physiology of mastication in rabbits (Ardran et al., 1958; Schumacher and Rehmer, 1960; Hertzberg et al., 1980; Weijs and Dantuma, 1981; Weijs and van der Wielen-Drent, 1982, 1983), knowledge of the histochemistry (Mabuchi et al., 1984) and physiological properties of masticatory muscles in rabbits is more limited. The superficial temporalis muscle of the rabbit con- sists predominantly of fast muscle fibers that are low in oxidative enzymes. Likewise, physiological experiments show ST to have rapid contraction times.

The average contraction time of the rabbit ST measured in situ $(25.5 \mathrm{~ms})$ is similar to comparable measurements taken from rabbit digastric muscles, which have TPTs ranging between 18 and $29 \mathrm{~ms}$ (Muhl et al., 1978). The TPT of ST in rabbits is also similar to that of the temporalis muscle reported for other mammalian species. For example, mean TPTs of ST of $18.3 \mathrm{~ms}$ have been reported for opossums (Thexton and Hiiemae, 1975), $33.8 \mathrm{~ms}, 28 \mathrm{~ms}$, and $11.4 \mathrm{~ms}$ for cats (Tamari et al., 1973; MacKenna and Turker, 1978; Taylor et al., 1973), and $22.4 \mathrm{~ms}$ for rhesus monkeys (Faulkner et al., 1982). These researchers have also reported similar values of TPT for the masseter muscle in various mammalian species, including 15.8 $\mathrm{ms}$ in opossums, $17.8 \mathrm{~ms}, 30 \mathrm{~ms}$, and $13.1 \mathrm{~ms}$ in cats, and $25.5 \mathrm{~ms}$ in rhesus monkeys.

Analysis of our results indicates that, although differences between groups in the morphological and physiological properties of ST were found, our original hypothesis was not confirmed. No evidence of ST hypertrophy (increase in mass) was found in the experimental animals, although some hypertrophy of Type IIa fibers was evident, as indicated by increases in cross-sectional area. ST adapted chiefly by an increase in the proportion of the relative cross-sectional area of oxidative (Type IIa) fibers and by an increase in fatigue-resistance properties. Analysis of the results thus suggests that ST in the experimental animals adapted by acquiring the ability for a larger number of its fibers to be recruited with greater frequency without fatigue. This change in the proportions of the relative crosssectional areas of types IIa and IIb fibers resulted in a prolongation of contraction time of the muscle, which has also been demonstrated in monkey masticatory muscles after the placement of a bite-opening appliance (Faulkner et al., 1982). 

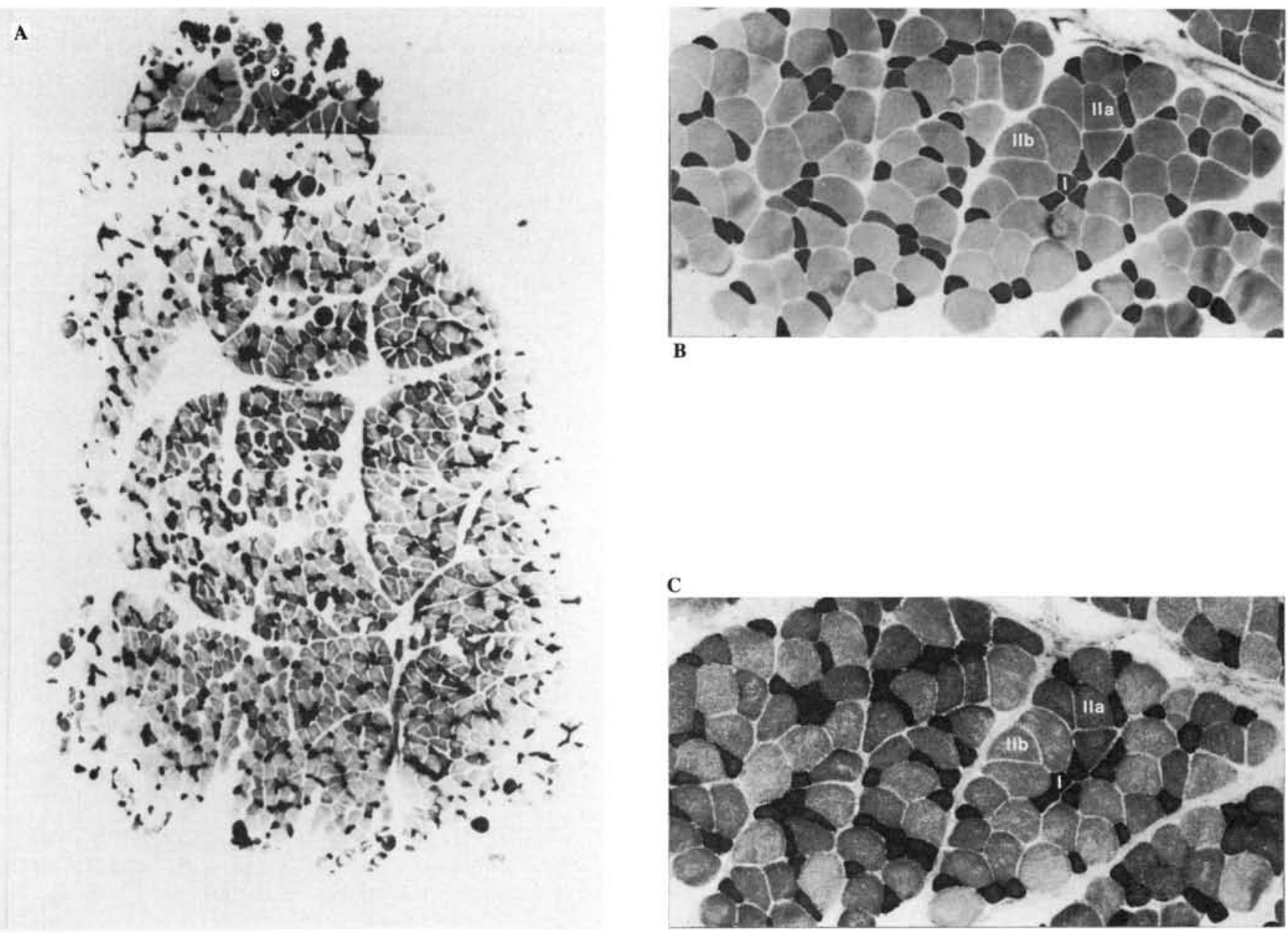

Fig. 3-Montage indicating the entire cross-section of the middle portion of the rabbit superficial temporalis muscle stained for myofibrillar ATPase following pre-incubation at $\mathrm{pH} 4.5$ (A). Higher-power view of the rabbit superficial temporalis muscle stained for myofibrillar ATPase, pre-incubation at $\mathrm{pH} 4.5$ (B), and SDH (C). Type I, Type IIa, and Type IIb fibers are identified on the higher-power photomicrographs.

TABLE 1

CRANIUM, BODY, AND MUSCLE SIZE IN CONTROL AND EXPERIMENTAL ANIMALS

\begin{tabular}{|c|c|c|c|c|c|}
\hline & \multicolumn{2}{|c|}{ Controls } & \multicolumn{3}{|c|}{ Experimental } \\
\hline & Mean & SD & Mean & SD & \\
\hline Skull Length - initial $(\mathrm{cm})$ & 7.94 & 0.50 & 7.53 & 0.13 & - \\
\hline Skull Width — initial (cm) & 4.20 & 0.26 & 4.00 & 0.27 & - \\
\hline Body Weight - initial (g) & 1344 & 320 & 1240 & 114 & - \\
\hline Skull Length - final (cm) & 8.92 & 0.40 & 9.13 & 0.34 & - \\
\hline Skull Width - final $(\mathrm{cm})$ & 4.50 & 0.33 & 4.33 & 0.22 & - \\
\hline Body Weight - final (g) & 2709 & 421 & 1934 & 704 & * \\
\hline \multicolumn{6}{|l|}{ Superficial Temporalis } \\
\hline Weight (g) & 0.31 & 0.07 & 0.26 & 0.13 & - \\
\hline Medical Pterygoid Weight (g) & 3.09 & 0.32 & 2.72 & 0.28 & - \\
\hline
\end{tabular}

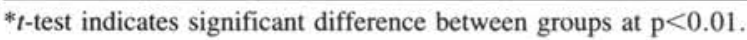

A longer TPT, higher oxidative capacities, and greater resistance to fatigue of IIa fibers, compared with IIb fibers, were described by Close (1964) in the rat. Similar differences in limb muscles have been described after long-term low-frequency stimulation (Salmons and Henriksson, 1981; Mabuchi et al., 1982) or after training with highly repetitive, low-resistance movements (for review, see Edgerton, 1978). By contrast, overloading of the soleus muscle by myectomy of its
TABLE 2

POST-SURGICAL BITE FORCE MEASUREMENTS (IN NEWTONS) Controls Experimental Mean SD Mean SD

\begin{tabular}{lllll}
\hline Maximum Stimulated Bite Force - 2nd week & 34.3 & 3.0 & 14.7 & $7.3 *$
\end{tabular} $\begin{array}{lllll}\text { Maximum Stimulated Bite Force — } 4 \text { th week } & 47.8 & 9.9 & 17.0 & 12.1\end{array}$ * $\begin{array}{lllll}\text { Maximum Stimulated Bite Force }-6 \text { th week } & 55.9 & 13.2 & 22.3 & 20.0\end{array}$ * $\begin{array}{lllll}\text { Maximum Stimulated Bite Force }-8 \text { th week } & 72.5 & 17.0 & 28.1 & 14.5\end{array}$

${ }^{*} t$-test indicates significant difference between groups at $\mathrm{p}<0.01$.

synergists has been shown to result in hypertrophy of this muscle without a shift in the oxidative capabilities of the Type II fibers (Rowe and Goldspink, 1968; Ianuzzo et al., 1976; Vaughan and Goldspink, 1979). Hypertrophy has also been found in skeletal muscle following high-resistance efforts with low repetitions (Fitts and Holloszy, 1977; Edgerton, 1978; Dons et al., 1979).

It is likely that muscular forces during oral activities in our caged rabbits are relatively low compared to possible maximum forces. Mastication in these rabbits would approximate a training regimen of low resistance and high repetitions. Rabbits in the wild engage in more strenuous oral activities, such as eating bark in the winter months (Hickie, 1940; Dalke and 
TABLE 3

CONTRACTILE PROPERTIES OF SUPERFICIAL TEMPORALIS MUSCLES MEASURED IN SITU

\begin{tabular}{lrrrrrr}
\hline \hline & \multicolumn{3}{c}{ Controls } & & \multicolumn{3}{c}{ Experimental } \\
\cline { 2 - 3 } \cline { 6 - 7 } & Mean & SD & & Mean & SD & \\
\hline Peak Tetanic Tension (n) & 3.8 & 1.4 & 4.5 & 2.4 & - \\
Time-to-peak Tension (ms) & 25.5 & 4.3 & & 30.1 & 3.7 & $* *$ \\
One-half Relaxation Time (ms) & 23.0 & 6.2 & & 21.7 & 3.0 & - \\
Peak Twitch Tension (n) & 0.9 & 0.4 & & 1.1 & 0.5 & - \\
Peak Twitch Tension - final*(n) & 0.4 & 0.2 & 0.7 & 0.2 & $* *$ \\
\hline
\end{tabular}

*Twitch tensions after five minutes of stimulation at $3 \mathrm{~Hz}$.

${ }^{*} t$-test indicates significant difference between groups at $\mathrm{p}<0.05$

TABLE 4

HISTOCHEMICAL PROPERTIES OF SUPERFICIAL TEMPORALIS MUSCLE

\begin{tabular}{lrrrrrrr}
\hline & \multicolumn{2}{c}{ Controls } & & \multicolumn{3}{c}{ Experimental } \\
\cline { 2 - 3 } \cline { 5 - 6 } \cline { 5 - 6 } & Mean & \multicolumn{1}{c}{ SD } & & Mean & \multicolumn{1}{c}{ SD } & \\
\hline \% Area Type I Fibers & 9.4 & 3.8 & & 11.0 & 4.2 & - \\
\% Area Type Ha Fibers & 17.1 & 10.8 & & 29.3 & 8.9 & $* *$ \\
\% Area Type IIb Fibers & 73.5 & 9.4 & & 59.7 & 10.6 & $* *$ \\
\% Type I Fibers & 30.0 & 7.3 & & 29.4 & 5.9 & - \\
\% Type Ila Fibers & 24.6 & 11.3 & & 34.4 & 9.3 & - \\
\% Type Ilb Fibers & 45.4 & 7.8 & & 36.2 & 8.8 & - \\
Type I Fiber Area* & 983 & 305 & & 1045 & 154 & - \\
Type Ila Fiber Area* & 1703 & 373 & & 2370 & 261 & $* *$ \\
Type IIb Fiber Area* & 4617 & 1105 & 4360 & 472 & - \\
\hline
\end{tabular}

*Mean cross-sectional area of the various types of muscle fibers is given in $\mu \mathrm{m}^{2}$

$* * t$-test indicates significant difference between groups at $p<0.05$

Sime, 1941; Dusi, 1952; Pehrson, 1981). It is hypothesized that muscle hypertrophy might be expected if experiments were carried out using a diet that requires more strenuous masticatory activity, since the response of skeletal muscle is dependent on the magnitude of the changes in activity.

\section{Acknowledgments.}

The authors thank Dr. John Faulkner for assistance in the experimental phase of this project and for his comments on the manuscript, and Ms. Stephanie Riolo for her help in collecting the muscle histochemistry data.

\section{REFERENCES}

ARDRAN, G.; KEMP, F.H.; and RIDE, W.D.L. (1958): A Radiographic Analysis of Mastication and Swallowing in the Domestic Rabbit, Oryctolagus cuniculus (L.), Proc Zool Soc Lond 130:257274.

ARMSTRONG, R.B.; MARUM, P.; TULLSON, P.; and SAUBERT, C.W.I.V. (1979): Acute Hypertrophic Response of Skeletal Muscle to Removal of Synergists, J Appl Physiol Respirat Environ Exercise Physiol 46:835-842.

AVIS, V. (1959): The Relation of the Temporal Muscle to the Form of the Coronoid Process, Am J Phys Anthrop 17:99-104.

AVIS, V. (1961): The Significance of the Angle of the Mandible: An Experimental and Comparative Study, Am J Phys Anthrop 19:5561.

BEECHER, R.M. and CORRUCCINI, R.S. (1981): Effects of Dietary Consistency on Craniofacial and Occlusal Development in the Rat, Angle Orthod 51:61-69.

BEHRENTS, R.G. and JOHNSTON, L.E. (1984): Influence of the Trigeminal Nerve on Facial Growth and Development, Am J Orthodont 85:199-206.

BOUVIER, M. and HYLANDER, W.L. (1981): Effect of Bone Strain on Cortical Bone Structure in Macaques (Macaca mulatta), J Morphol 167:1-12.

BOUVIER, M. and HYLANDER, W.L. (1982): The Effect of Dietary Consistency on Morphology of the Mandibular Condylar Cartilage in Young Macaques (Macaca mulatta). In: Factors and Mechanisms Influencing Bone Growth, A.D. Dixon and B.G. Sarnat, Eds., New York: Alan R. Liss, Inc.

BOUVIER, M. and HYLANDER, W.L. (1984): The Effect of Dietary Consistency on Gross and Histologic Morphology in the Craniofacial Region of Young Rats, Am J Anat 170:117-126.

BOYD, T.G.; CASTELLI, W.A.; and HULKE, D.F. (1967): Removal of the Temporalis Muscle from its Origin: Effects on the Size and Shape of the Coronoid Process, J Dent Res 46:997-1000.

BYRD, K.E. and LUSCHEI, E.S. (1980): Cerebellar Ablation and Mastication in the Guinea Pig (Cavia porcellus), Brain Res 197:577581

CLOSE, R. (1964): Dynamic Properties of Fast and Slow Skeletal Muscles of the Rat During Development, J Physiol (Lond) 173:74 95.

DALKE, P.D. and SIME, P.R. (1941): Food Habits of the Eastern and New England Cottontails, $J$ Wildlife Management 5:216-228.

DECHOW, P.C. and CARLSON, D.S. (1983): A Method of Bite Force Measurement in Primates, $J$ Biomechan 16:797-802.

DONS, B.; BOLLERUP, K.; BONDE-PETERSEN, F.; and HANCKE, S. (1979): The Effect of Weight-lifting Exercise Related to Muscle Fiber Composition and Muscle Cross-sectional Area in Humans, Eur J Appl Physiol 40:95-106.

DUBOWITZ, V. and BROOK, N.H. (1973): Muscle Biopsy: Modern Approach. London: W.B. Saunders Co. Ltd.

DUSI, J.L. (1952): The Food Habits of Several Populations of Cottontail Rabbits in Ohio, $J$ Wildlife Management 16:180-186.

EDGERTON, V.R. (1978): Mammalian Muscle Fiber Types and their Adaptability, Amer Zool 18:113-125.

FAULKNER, J.A.; McCULLY, K.K.; CARLSON, D.S.; and McNAMARA, J.A., Jr. (1982): Contractile Properties of the Muscles of Mastication of Rhesus Monkeys Macaca mulatta Following Increase in Muscle Length, Arch Oral Biol 27:841-845.

FITTS, R.H. and HOLLOSZY, J.O. (1977): Contractile Properties of Rat Soleus Muscle: Effects of Training and Fatigue, Am J Physiol 233:C86-C91.

GARDNER, D.E.; LUSCHEI, E.S.; and JOONDEPH, D.R. (1980): Alterations in the Facial Skeleton of the Guinea Pig Following a Lesion of the Trigeminal Motor Nucleus, Am J Orthod 78:66-80.

GOLDBERG, A.L.; ETLINGER, J.D.; GOLDSPINK, D.F.; and JABLECKI, C. (1975): Mechanism of Work-induced Hypertrophy of Skeletal Muscle, Med Sci in Sports 7:248-261.

HERTZBERG, S.R.; MUHL, Z.F.; and BEGOLE, E.A. (1980): Muscle Sarcomere Length Following Passive Jaw Opening in the Rabbit, Anat Rec 197:435-440.

HICKIE, P. (1940): Cottontails in Michigan. Lansing, Michigan: Game Division, Michigan Department of Conservation, Franklin DeKleine Co.

HOLLOSZY, J.O. (1977): Contractile Properties of Rat Soleus Muscle: Effects of Training and Fatigue, Am J Physiol 233:C86-C91.

HOLLOSZY, J.O. and BOOTH, F.W. (1976): Biochemical Adaptations in Endurance Exercise in Muscle, Ann Rev Physiol 38:273291.

HOROWITZ, S.L. and SHAPIRO, H.H. (1951): Modifications of Mandibular Architecture Following Removal of Temporalis Muscle in the Rat, $J$ Dent Res 30:276-280.

IANUZZO, C.D.; GOLLNICK, P.D.; and ARMSTRONG, R.B. (1976): Compensatory Adaptations of Skeletal Muscle Fiber Types to a Long-term Functional Overload, Life Sciences 19:1517-1524.

JOLESZ, F. and SRETER, F.A. (1981): Development, Innervation, and Activity-pattern Induced Changes in Skeletal Muscle, Ann Rev Physiol 43:531-552.

MABUCHI, K.; PINTER, K.; MABUCHI, Y.; SRETER, F.; and GERGELY, J. (1984): Characterization of Rabbit Masseter Muscle Fibers, Muscle and Nerve 7:431 438.

MABUCHI, K.; SZVETKO, D.; PINTER, K.; and SRETER, F.A. (1982): Type IIB to IIA Transformation in Intermittently Stimulated Rabbit Muscles, Am J Physiol 242:C373-C381.

MACKENNA, B.R. and TURKER, K.S. (1978): Twitch Tension in 
the Jaw Muscles of the Cat at Various Degrees of Mouth Opening, Arch Oral Biol 23:917-920.

MOORE, W.J. (1965): Masticatory Function and Skull Growth, $J$ Zool Lond 146:123-131.

MOSS, M.L. (1972): The Regulation of Skeletal Growth. In: Regulation of Organ and Tissue Growth, New York: Academic Press, Inc., pp. 127-142.

MUHL, Z.F.; GRIMM, A.F.; and GLICK, P.L. (1978): Physiologic and Histologic Measurements of the Rabbit Digastric Muscle, Arch Oral Biol 23:1051-1059.

PEHRSON, A. (1981): Winter Food Consumption and Digestibility in Caged Mountain Hares. Proceedings of the World Lagomorph Conference (held in Guelph, Ontario, August, 1979), K. Myers and C.D. Macinnes, Eds., Guelph, Ontario: University of Guelph Press, pp. 732-742.

ROWE, R.W.D. and GOLDSPINK, G. (1968): Surgically Induced Hypertrophy in Skeletal Muscles of the Laboratory Mouse, Anat Rec 161:69-76.

SALMONS, S. and HENRIKSSON, J. (1981): The Adaptive Response of Skeletal Muscle to Increased Use, Muscle and Nerve 4:94-105.

SARNAT, B.G.; FEIGENBAUM, J.A.; and GROGMAN, W.M. (1977): Adult Monkey Coronoid Process After Resection of Trigeminal Nerve Motor Root, Am J Anat 150:129-138.

SCHUMACHER, G.H. and REHMER, H. (1960): Morphologische und Funktionelle untersuchungen an der Kaumuskulatur von $\mathrm{Or}$ yctolagus und Lepus, Morph Jb 100:678-705.
TAMARI, J.W.; TOMEY, G.F.; IBRAHIM, M.Z.M.; BARAKA, A.; JABBUR, S.J.; and BAHUTH, N. (1973): Correlative Study of the Physiologic and Morphological Characteristics of the Temporal and Masseter Muscles of the Cat, $J$ Dent Res 52:538-543.

TAYLOR, A.; CODY, F.W.J.; and BOSLEY, M.A. (1973): Histochemical and Mechanical Properties of the Jaw Muscles of the Cat, Exp Neurol 38:99-109.

THEXTON, A.J. and HIIEMAE, K.M. (1975): The Twitch-contraction Characteristics of Opossum Jaw Musculature, Arch Oral Biol 20:743-748.

VARGERVIK, K. and MILLER, J.A. (1984): Neuromuscular Patterns in Hemifacial Microsomia, Am J Orthod 86:33-42.

VAUGHAN, H.S. and GOLDSPINK, G. (1979): Fibre Number and Fibre Size in a Surgically Overloaded Muscle, J Anat 129:293303.

WASHBURN, S.L. (1947): The Relation of the Temporal Muscle to the Form of the Skull, Anat Rec 99:239-248.

WEIJS, W.A. and DANTUMA, R. (1981): Functional Anatomy of the Masticatory Apparatus in the Rabbit (Oryctolagus cuniculus L), Netherlands J Zool 31:99-147.

WEIJS, W.A. and VAN DER WIELEN-DRENT, T.K. (1982): Sarcomere Length and EMG Activity in Some Jaw Muscles of the Rabbit, Acta Anat 113:178-188.

WEIJS, W.A. and VAN DER WIELEN-DRENT, T.K. (1983): The Relationship Between Sarcomere Length and Activation Pattern in the Rabbit Masseter Muscle, Arch Oral Biol 28:307-315. 